\title{
АЗЕОТРОПНЫЕ ХАРАКТЕРИСТИКИ БИНАРНЫХ СИСТЕМ, ОБРАЗОВАННЫХ АЛКЕНАМИ И ТИОФЕНОМ С ВОДОЙ И СПИРТАМИ
}

В настоящей работе при нормальном давлении определялись температуры кипения и составы гомоазеотропов, образованных гексеном-1 и тиофеном со спиртами, а также гетероазеотропов, образованных водой с гексеном-1, гептеном-1, октеном-1 и тиофеном. При ректификационном выделении азеотропов использовалась колонка с головкой новой конструкции. Результаты, полученные для гомоазеотропов в этой работе и ранее $\left[{ }^{1,2}\right]$, были использованы для расчета констант корреляционных уравнений. Для гетероазеотропов, образованных компонентами с ограниченной взаимной растворимостью, предложен критерий для оценки надежности данных о составе.

\section{Экспериментальная часть}

При перегонке гетероазеотропов в колонке с головкой обычной конструкции флегма охлаждается и зачастую расслаивается. Расслаиваются также отбираемые пробы гетероазеотропов. Для устранения этих недостатков в данной работе использовалась колонка, конструкция головки которой позволяла поддерживать температуру флегмы, близкой к температуре равновесия жидкость-пар, и отбирать пробы дистиллята из паровой фазы. Головка колонки изображена на рисунке.

Головка снабжена дефлегматором с воздушным охлаждением.

При установлении рабочего режима калорифер (6) выключается и необходимая для нормальной работы флегма образуется за счет охлаждения радиатора (4) потоком воздуха, подаваемого вентилятором. Вследствие небольшой теплопередачи стенки колонки сохраняют температуру, близкую к температуре паро-жидкостного равновесия. При отборе дистиллята подаваемый в радиатор воздух подогревают калорифером (6) в импульсном режиме с помощью временного реле по избранной программе. Установление режима контролируется термометром (5). Режим можно менять как изменением температуры потока воздуха, так и изменением продолжительности импульсов обогрева и интервалов между ними.

Наполнитель колонки был изготовлен в виде спирали из нержавеющей стали диаметром 0,2 мм, намотанной винтообразно с диаметром витка 5 м.. Эта спираль была скручена в спираль типа «ламповой щетки» и полученные таким образом витки были сплющены. Шаг сложной спирали 5 мм. Насадка была помещена в стеклянную трубку диаметром $9 \mu \mu$. 


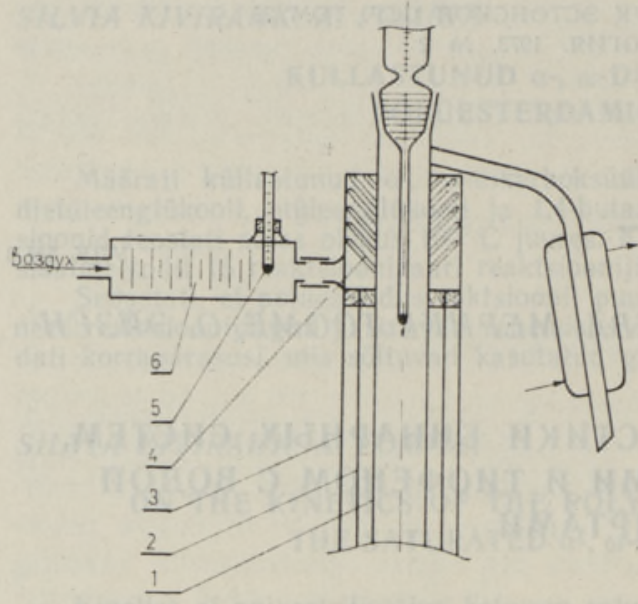

Головка колонки

I - колонка, 2 - обогревательная рубашка, 3 - теплозащитный кожух, 4 - радиатор, 5 - термометр, 6 - калорифер.

Рабочий режим в колонке легко регулируется, отличается устойчивостью и устанавливается в течение 10-15 мин. Эффективность колонки была определена с помощью смеси бензол - 1,2-дихлорэтан равной 14 ТТ. Количество исходной смеси составляло $20 \mathrm{M}$.

Состав бинарных смесей определялся хроматографически на УХ-1 в колонке длиной 3 м с наполнителем из $20 \%$ полиэтиленгликоля 4000 на хромосорбе $W$ в интервале температур $\quad 70-100^{\circ} \mathrm{C} . \quad$ Газ-носитель - гелий. Гетероазеотропные смеси предварительно гомогенизировались ацетоном. Методика ректификационного выделения азеотропов и способ расчета их хроматограмм изложены в [ $\left.{ }^{3}\right]$.

Использованные в работе вещества имели следующие характеристики:

$\begin{array}{lcc} & \text { T. кип, С } & n_{D}^{2 n} \\ \text { гексен-1 } & 63,5 & 1,3879 \\ \text { гептен-1 } & 93,6 & 1,4002 \\ \text { октен-1 } & 121,3 & 1,4087 \\ \text { гексан } & 68,7 & 1,3750 \\ \text { нонан } & 150,8 & 1,4054 \\ \text { хлороформ } & 61,2 & 1,4460 \\ \text { бензол } & 80,2 & 1,5011 \\ \text { тиофен } & 84,1 & 1,5286 \\ \text { изопропанол } & 82,5 & 1,3773 \\ \text { пропанол } & 97,2 & 1,3854 \\ \text { вода } & 100,0 & 1,3330\end{array}$

Для отработки методики и проверки надежности получаемых данных о составах и температурах кипения азеотропов были определены азеотропные характеристики некоторых ранее изученных смесей. Результаты определения сопоставляются в табл. 1 с литературными данными.

Из данных, приведенных в табл. 1, следует, что расхождение между экспериментальными и литературными данными не выходит за пределы возможных ошибок анализа [9].

\section{Экспериментальные данные и их обсуждение}

Результаты исследования гомо- и гетероазеотропов помещены в табл. 2 и 3 соответственно. Полученные нами данные о составе азеотропа этанол-тиофен существенно отличаются от данных, приведенных в справочнике [ $\left.{ }^{9}\right]\left(x_{1}=0,401\right.$, т. кип. $\left.70,0^{\circ}\right)$. При исследовании равновесия жидкость-пар в системе гексен-1-пропанол в интервале концентра- 
Сравнение опытных данных о температурах кипения и составах некоторых азеотропов с литературными данными

\begin{tabular}{|c|c|c|c|c|c|c|c|c|}
\hline \multirow{2}{*}{ Азеотроп } & \multicolumn{2}{|c|}{$\begin{array}{c}\text { Oпытные } \\
\text { данные }\end{array}$} & \multicolumn{2}{|c|}{$\begin{array}{c}\text { Литературные } \\
\text { данные и } \\
\text { ссылка }\end{array}$} & \multirow{2}{*}{$p_{1}$} & \multirow{2}{*}{$p_{2}$} & \multirow{2}{*}{$p_{1}^{0}$} & \multirow{2}{*}{$p_{2}^{0}$} \\
\hline & $\begin{array}{c}\text { T. кип., } \\
{ }^{\circ} \mathrm{C}\end{array}$ & $x_{1}$ & $\begin{array}{l}\text { Т. кипा., } \\
{ }^{\circ} \mathrm{C}\end{array}$ & $x_{1}$ & & & & \\
\hline \multicolumn{9}{|l|}{ Хлороформ(1) } \\
\hline Изопропанол (1) & 00,4 & 0,780 & 60,4 & $0,182\left[{ }^{\circ}\right]$ & & & & \\
\hline $\begin{array}{c}\text {-гептен-1 (2) } \\
\text { Вода(1)-нонан (2) }\end{array}$ & 76.0 & 0.587 & 74.7 & $0.584[5]$ & - & $\overline{107}$ & - & $\overline{102}$ \\
\hline Вода (1)-бензол (2) & $\begin{array}{l}9,0 \\
69,3\end{array}$ & 0,295 & $\begin{array}{l}90,0 \\
69,25\end{array}$ & $0,296[7]$ & $\begin{array}{l}22,0 \\
224,2\end{array}$ & 535,8 & 225,9 & 537,1 \\
\hline Вода(1)-бутанол (2) & 92,6 & 0,745 & 92,6 & $0,757\left[{ }^{8}\right]$ & 566,2 & 193,8 & 579,9 & $292, \tilde{5}$ \\
\hline
\end{tabular}

Таблица 2

Результаты определения температур кипения и составов гомоазеотропов и сравнение их с расчетными данными

\begin{tabular}{|c|c|c|c|c|c|c|}
\hline \multirow[b]{2}{*}{ Азеотроп } & \multicolumn{3}{|c|}{ Экспериментальные данные } & \multicolumn{3}{|c|}{ Расчетные данные } \\
\hline & Т. кип., & $x_{1}$ & $x_{2}$ & Т. кипг, & $x_{1}$ & $x_{2}$ \\
\hline Гексен-1(1)- & & & & & & \\
\hline $\begin{array}{l}\text { метанол (2) * } \\
\text { Гексен-1(1)- }\end{array}$ & 48,2 & 0,591 & 0,409 & 48,4 & 0,591 & 0,409 \\
\hline этанол $(2) *$ & 54,8 & 0,720 & 0,280 & 55,1 & 0,721 & 0,279 \\
\hline $\begin{array}{l}\text { Гексен-1 (1)- } \\
\text { изопропанол (2) * } \\
\text { Гексен-1 (1)- }\end{array}$ & 59,2 & 0,813 & 0,187 & 56,8 & 0,761 & 0,239 \\
\hline Гексен-1 (1)- & 61,7 & 0,902 & 0,098 & 61,0 & 0,900 & 0,100 \\
\hline $\begin{array}{l}\text { Тиофен (1)- } \\
\text { метанол (2) * } \\
\text { Тиофен (1)- }\end{array}$ & 59,4 & 0,333 & 0,667 & 59,3 & 0,330 & 0,670 \\
\hline $\begin{array}{l}\text { Тиофен (1)- } \\
\text { этанол (2) } \\
\text { Тиофен (1)- }\end{array}$ & 69,6 & 0,499 & 0,501 & 70,0 & 0,504 & 0,496 \\
\hline $\begin{array}{l}\text { изопропанол (2) } \\
\text { Тиофен(1)- }\end{array}$ & 74,2 & 0,534 & 0,466 & 72,7 & 0,559 & 0,441 \\
\hline пропанол (2) & 80,3 & 0,751 & 0,249 & 79,9 & 0,748 & 0,252 \\
\hline
\end{tabular}

* Азеотропные характеристикн определены на колонке с головкой обычной конструкции $\left[{ }^{1}, 2\right]$.

ций $0,1-0,9$ при $55^{\circ}$ азеотроп обнаружен не был $\left.{ }^{2}\right]$. Для остальных систем результаты определения азеотропных характеристик в литературе отсутствуют.

Число вновь выявляемых азеотропных систем быстро растет. В новом справочнике по азеотропным смесям их количество превышает 21000. Однако не все данные могут считаться достаточно надежными. Отсутствие критерия надежности вынуждает авторов помещать в справочниках все существующие данные, несмотря на их весьма значительные рас. хождения.

При оценке надежности составов и температур кипения гомоазеотропов дело ограничивается выведением эмпирических уравнений, позво ляющих оценить лишь взаимную согласованность этих характеристик 
Таблица 3

Результаты определения температур кипения и составов гетероазеотропов и сравнение их с расчетными данными

\begin{tabular}{|c|c|c|c|c|c|c|c|c|c|}
\hline & \multirow[b]{2}{*}{ Азеотроп } & \multicolumn{4}{|c|}{ Экспериментальные данные } & \multicolumn{4}{|c|}{ Расчетные данные } \\
\hline & & $\begin{array}{l}\text { T. кип., } \\
{ }^{\circ} \mathrm{C}\end{array}$ & $x_{1}$ & $p_{1}$ & $p_{2}$ & $p_{1}^{0}$ & $p_{2}^{0}$ & $x_{1}$ & Т. кип., \\
\hline $\begin{array}{l}\text { Вода(1) } \\
\text { Вода(1) } \\
\text { Вода(1 } \\
\text { Вода(1) }\end{array}$ & $\left\{\begin{array}{l}\text { - гексен-1 (2) } \\
\text { - гептен-1 (2) } \\
\text { - октен-1 (2) } \\
\text { - тиофен (2) }\end{array}\right.$ & $\begin{array}{l}58,4 \\
77,1 \\
88,6 \\
72,3\end{array}$ & $\begin{array}{l}0,162 \\
0,410 \\
0,647 \\
0,326\end{array}$ & $\begin{array}{l}123,1 \\
311,6 \\
481,7 \\
247,8\end{array}$ & $\begin{array}{l}636,9 \\
448,4 \\
268,3 \\
512,2\end{array}$ & $\begin{array}{l}138,6 \\
315,3 \\
498,4 \\
258,0\end{array}$ & $\begin{array}{l}644.5 \\
453,0 \\
276,3 \\
520,1\end{array}$ & $\begin{array}{l}0,177 \\
0,410 \\
0,643 \\
0,332\end{array}$ & $\begin{array}{l}56,1 \\
78,0 \\
88,4 \\
72,6\end{array}$ \\
\hline
\end{tabular}

Таблица 4

Проверка данных о составе гетероазеотропа вода-1,2-дихлорэтан

\begin{tabular}{l|l|l|l|l|l}
\hline T. кип., ${ }^{\circ} \mathrm{C}$ & $x_{1}$ & $p_{1}$ & $p_{2}$ & $p_{1}^{0}$ & $p_{2}^{0}$ \\
\hline
\end{tabular}

$\begin{array}{llllll}71,5 & 0,400 & 304,0 & 456,0 & 249,4 & 520,8 \\ 72,0 & 0,314 & 238,6 & 521,4 & 254,8 & 529,5 \\ 71,6 & 0,329 & 250,0 & 510,0 & 250,4 & 522,5 \\ 72,0 & 0,571 & 434,0 & 326,0 & 254,8 & 529,5 \\ 72,28 & 0,357 & 271,3 & 488,7 & 257,8 & 534,4 \\ 75,5 & 0,329 & 250,0 & 510,0 & 295,2 & 593,4 \\ 70,0 & 0,323 & 245,5 & 514,5 & 233,7 & 495,5\end{array}$

для азеотропов определенной серии. Для расчета составов нами были использованы уравнения [10]

$$
\begin{gathered}
x_{\text {тиоф }}=0,5820+0,0129\left(t_{\text {сп }}-t_{\text {тиоф }}\right), \\
x_{\text {гекс }}=0,5780+0,0097\left(t_{\text {сп }}-t_{\text {гекс }}\right)
\end{gathered}
$$

и для расчета температур кипения - уравнения [11]

$$
\begin{aligned}
& t_{\mathrm{a} 3}^{\text {гекс }}=-12,75+1,313 t_{\mathrm{cn}}-0.0057 t_{\mathrm{cn}}^{2}, \\
& t_{\mathrm{a} 3}^{\text {тиоф }}=-33,90+1,977 t_{\mathrm{cn}}-0,0083 t_{\mathrm{cn}}^{2},
\end{aligned}
$$

константы которых определялись методом наименьших квадратов по приведенным в настоящей работе и опубликованным ранее $\left[{ }^{1,2}\right.$ данным для азеотропов, содержащих нормальные спирты. Сравнение с результатами опыта в табл. 2 показывает, что для азеотропов, образованных нормальными спиртами и исследованных в колонках различной конструкции, наблюдается хорошее совпадение рассчитанных и измеренных данных. В то же время для расчета азеотропных свойств смесей, содержащих изопропиловый спирт, приведенные выше уравнения менее пригодны.

Для гетероазеотропов, образованных компонентами с ограниченной взаимной растворимостью, известным критерием надежности может быть соотношение

$$
P \cdot x_{i}^{\mathrm{a} 3}=p_{i}^{\text {pacप }}<p_{i}^{0}
$$

где $P$ - общее давление, $x_{i}^{\text {as }}-$ молярная доля, $p_{i}^{\text {расч }}-$ парциальное давление, рассчитанное в предположении идеальности пара, $p_{i}^{0}-$ давление пара $i$-го компонента. Әто неравенство является следствием условия устойчивости жидкой фазы относительно непрерывных изменений 


$$
d \mu_{i} d x_{i} \geqslant 0, \quad T, P=\text { const, }
$$

где $\mu_{i}=\mu_{i}^{0}(T)+R T \ln p_{i}$ и $x_{i}-$ химический потенциал и молярная доля $i$-го компонента в системе.

Далеко не все существующие экспериментальные данные удовлетворяют этому простому критерию. Так, например, из девяти результатов определения азеотропных характеристик системы вода - 1,2-дихлорэтан, приведенных в справочнике []ㅡㄹ и помещенных в табл. 4, только для двух (2 и 3-го) соблюдается приведенное выше неравенство.

Естественно, что рассматриваемый критерий является надежным только при условии наличия точных данных о температуре кипения гетероазеотропа и давлении паров компонентов. При проверке составов азеотропов, полученных в настоящей работе, значения $p_{i}^{0}$ были рассчитаны по данным, приведенным в [12-14].

Чем меньше взаимная растворимость компонентов, тем ближе $p_{i}$ к $p_{i}^{0}$ и тем строже выполняется отношение

$$
\left(\frac{x_{1}}{x_{2}}\right)^{\text {a3 }}=\frac{p_{1}}{p_{2}} \approx \frac{p_{1}^{6}}{p_{2}^{0}},
$$

позволяющее производить простой расчет составов при условии, что температура кипения гетероазеотропа известна. Результаты расчета составов исследованных нами гетероазеотропов приведены в табл. 3 .

Температура кипения гетероазеотропов была рассчитана с некоторой погрешностью из уравнения Сколника

$$
\lg \left(100-t_{\text {аз }}\right)=5,01-0,01\left(273,2+t_{\text {угл }}\right),
$$

константы которого определены методом наименьших квадратов по данным о системах углеводород-вода [15].

Как следует из сравнения результатов эксперимента и расчета, наибольшее расхождение между ними наблюдается для системы вода гексен-1. Однако отношение давлений паров компонентов при таком изменении температуры изменяется очень мало и почти не сказывается на результате расчета состава.

\section{ЛИ Т Е Р А Т У Р А}

1. К уд ря вц ев а Л., Э й з ен О., Ж. прикл. химии, 43, 708 (1970).

2. Кудрявцев а Л., В ийт Хелле, Эйзен О., Изв. АН ЭССР, Хим. Геол., 18, 346 (1969).

3. Куд рявцев а Л. С., Э йзен О. Г., Сус а рев М. П., Ж. физ. химии, 40, 1285 (1966).

4. С усарев М. П., Кудрявцев а Л. С., М атушкевич Э. А., Ж. физ. химии, 37,2672 (1963).

5. Кудрявцева Л., Вийт Хелле, Эйзен О., Изв. АН ЭССР, Хим. Геол., 19. $22(1970)$.

6. Horsley L. H., Azeotropic Data II, Washington DC, 1962.

7. Horsley L. H., Azeotropic Data I, Washington DC, 1952

8. Кудрявцева Л. С., Сусарев М. П., Эй зен О. Г., Ж. физ. химии, 40, $1652(1966)$.

9. Огородников С. К., Л естева Т. М., Ког ан В. Б., Азеотропные смеси, Л., 1971 .

10. Yosh imoto T., Nippon Kagaku Zasshi, 83, 505 (1962).

11. Лестев а Т. М., Ж. физ. химии, 45,1477 (1971).

12. Вей сбе егер А., Проска уэр Э., Риддик Дж., Гупп Э,, Органические растворители, ИЛ., 1958.

13. Selected Values of Properties of Hydrocarbons and Related Compounds, APJ Research Project 44, Thermodynamics Research Center, Texas ACM University, Texas. 
14. Физико-химические свойства индивидуальных углеводородов. Под редакцией проф. В. М. Татевского. М., 1960.

15. Кудрявцев а Л. С., Т ооме М. Ю., Сусарев М. П., Ж. физ. химии, 46, 1698 (1972).

Институт химии

Академии наук Эстонской ССР
Поступила в редакцию $30 / \mathrm{V} 1972$

V. MIHKELSON, L. KUDRJAVTSEVA, MERIKE TOOME, O. EISEN

\section{ANDMEID TIOFEENI JA ALKEENIDE POOLT VEE JA ALKOHOLIDEGA MOODUSTATAVATE BINAARSETE ASEOTROOPSETE SEGUDE KOOSTISE KOHTA}

Binaarsete aseotroopsete segude eraldamiseks rektifikatsiooni teel kasutati uudse konstruktsiooniga kolonnipead. Segude koostis määrati gaasikromatograafiliselt. Eksperimentaalseid andmeid aluseks võttes arvutati vähimruutude meetodil empiiriliste võrrandite konstandid. Eksperimentaalseid ja arvutatud tulemusi vôrreldi omavahel ning kontrolliti heterogeensete aseotroopsete segude kohta saadud andmete usaldusväärsust.

W. MICHKELSON, L. KUDRJAWZEWA, MERIKE TOOME, O. EISEN

\section{DATEN UBER BINÄRE AZEOTROPE, WELCHE VON DEN ALKENEN UND VON THIOPHEN MIT ALKOHOLEN UND WASSER GEBILDET WERDEN}

Binäre Homo- und Heteroazeotrope wurden bei 760 Torr unter Verwendung der Destillationskolonne mit einem speziellen «azeotropen Kolonnenkopf» hergestellt. Die Zusammensetzung der Azeotrope wurde gaschromatographisch analysiert. Die Resultate vergleicht man mit Werten, die nach bekannten empirischen Gleichungen berechnet wurden. Die Zusammensetzung der Heteroazeotrope wurde auf Zuverlässigkeit geprüft. 